\title{
Knowledge Spillover and Positive Environmental Externality in Agricultural Decision Making under Performance-Based Payment Programs
}

\author{
Hongxing Liu $\odot$, and Christopher S. Ruebeck
}

\begin{abstract}
Agricultural activities have imposed significant impacts on water resources, leading to hypoxic zones and harmful algal blooms all over the world. Government agencies, nongovernmental organizations, and individuals have been making various efforts to reduce this non-point source pollution. Among those efforts, even the more costeffective examples of performance-based environmental payment programs generally have low participation rates. We investigate the effects of externalities in farmers' decisions on neighboring farms, incorporating both a knowledge spillover effect and a positive environmental outcome externality of farmers' best-management practice (BMP) adoption decisions. Our focus is on how these effects may influence the outcome of performance-based payment programs and how policy makers might recognize these effects in the design of cost-effective policies to promote program participation and BMP adoption. Rather than imposing an assumption of profit-maximization or forward-looking behavior, we allow outcomes to emerge from interactions among neighboring farmers. We recommend cost-effective policies across communities depending on their composition. It is more cost-effective to target communities with fewer innovators and/or target the programs towards the least-innovative individuals.
\end{abstract}

Keywords: agent-based modeling, agricultural decision, externality, knowledge spillover, performance-based payment programs, non-point source pollution

\section{Introduction}

Agricultural activities (nonpoint source) and urban development (point source) have imposed significant impacts on water resources, leading to harmful algal blooms (HABs) and hypoxic zones in every U.S. coastal state and around the world (NOAA, 2019). HABs affect not only the marine ecosystems but also fisheries, human health, recreational industries, and related local economies.

Department of Economics, Lafayette College. Correspondence: Hongxing Liu, 30 South College Drive, William E. Simon Center, Easton, PA, 18042. Email: liuho@lafayette.edu

Agricultural and Resource Economics Review 49/2 (August 2020) 270-290

(C) The Author(s) 2020. This is an Open Access article, distributed under the terms of the Creative

Commons Attribution licence (http://creativecommons.org/licenses/by/4.0/), which permits unrestricted re-use, distribution, and reproduction in any medium, provided the original work is 
Both the accumulation of nutrients (in soil and in bodies of water) and global climate change are leading to HABs with increasing frequency. To combat these harmful effects, efforts involving government agencies, nongovernmental organizations, and community-based groups have sought to create innovative mechanism designs that can reduce nutrient runoff and improve water quality. These include voluntary cost-share payments for best management practices (BMPs), regulatory limits such as total maximum daily load (TMDL), fertilizer taxes, and water quality trading (WQT).

Relatively recently, there has been growth in pay-for-performance (PFP) conservation programs such as the Maryland Nutrient Trading Program (Duke et al. 2020; Palm-Forster et al. 2016b; Claassen and Weinberg 2006; Winsten and Hunter 2011). These programs are similar to Payments for Ecosystem Service (PES) programs in that farmers participate voluntarily but receive payments based on the environmental benefits generated from their conservation practices rather than being paid for the practices themselves (e. g., Environmental Quality Incentive Program). Studies have shown that the performance-based programs can be more cost-effective and offer flexibility as compared to the pay-for-practice programs (Fales et al. 2016; Claassen and Weinberg 2006). In PFP programs, environmental outcomes such as phosphorus or nitrogen reduction are usually calculated by field-scale models (e.g., Maryland Nutrient Trading Tool) that build on hydrologic models such as the Soil and Water Assessment Tool (SWAT) or the Agricultural Policy Environmental eXtender (APEX) Model (Muenich et al. 2017). These models, though differing from one another in some details, all take into account the inherent spatial heterogeneity in fields' physical characteristics such as soil productivity, hydrologic balance, and climate inputs. Thus, PFP programs can increase efficiency by moving away from uniform payments and toward firstbest differentiated policies.

While we have seen that these programs can provide greater flexibility on the choice and timing of conservation practices, reduce overall compliance costs, and encourage voluntary participation of non-point sources within the watershed (EPA/NPDES 2019), experience has also shown that the number of participants from both point and nonpoint sources has been limited, and the value of offsets has been minimal (Stephenson and Shabman 2017; U.S. Environmental Protection Agency, 2008; Hanson and McConnell 2008; Newburn and Woodward 2012). One of the main reasons for the limited participation to this point is that, even though theoretically cost-effective, these programs still impose high transaction costs on the participants. Previous research has focused largely on the transaction costs and information asymmetry of WQT participation or PES payment for environmental service contracts in general (Hanson and McConnell 2008; Newburn and Woodward 2012; Nguyen et al. 2013; Palm-Forster et al. 2016a; Peterson et al. 2015; Woodward and Kaiser 2002). Studies have found that the costs created by asymmetric information-formulating, negotiating, and monitoring contracts-can significantly decrease the 
efficiency of the programs (Palm-Forster et al. 2016a; Peterson et al. 2015; Stephenson and Shabman 2017), in part because they disincentivize participation.

Studies have also viewed the decision to adopt conservation practices from the perspective of individual decision-making and as a part of social interactions. In terms of an individual farmer's motivation to adopt conservation practices, the literature has found that farmers' attitudes towards "environmental stewardship" are an important component of their decision-making in addition to their own economic concerns (e.g., Berger 2001; Carlisle 2016; Reimer, Thompson, and Prokopy 2012). Studies have found that farmers' concerns about the environmental impact of agriculture can act as intrinsic motivators for adopting conservation practices (e.g., Reimer and Prokopy 2014; Ryan et al. 2003); that farmers' perception of the efficacy of particular conservation practices is a determining factor in their decisions to use those practices (e.g., Zhang et al. 2016); and that awareness of technical information on BMPs can promote adoption (e.g., Lemke et al. 2010). Others have shown that farmers' decisions can be influenced by farmland characteristics such as field size, crop choice, and irrigation choice (e.g., Bergtold et al. 2012); by demographic characteristics such as education, gender, and age (e.g., Druschke and Secchi 2014; Soule, Tegene, and Wiebe 2000); and by risk and time preferences (e.g., Rolfe and Gregg 2015).

These factors that influence individual farmers' decisions can also be viewed in a social context where knowledge spillover can promote farmers' adoption of new technology, especially among neighbors. Investigations have explored the influence of social networks (Carlisle 2016), trust and social embeddedness (Breetz et al. 2005; Mariola 2012), and social norms (Welch and Marc-Aurele 2001; Wollni and Andersson 2014). Much of the literature on knowledge spillover in farmers' technology adoption decisions is based on data from developing countries and Northern European countries. Evidence shows that neighborhood effects exist in farmers' decision-making (Case 1992; Davey and Furtan 2008; Läpple et al. 2017; Miyata and Manatunge 2004; Storm et al. 2015), especially for smaller, less costly, and reversible decisions such as milk recording (Baerenklau 2005). More specifically, farmers with neighbors who have already adopted the new technology may lower their learning costs and thus be more likely to adopt (Case 1992; Holloway, Lacombe, and LeSage 2007; Lewis et al. 2011). The neighborhood effect depends not only on farmers' neighbors' choices but also on their neighbors' and their own characteristics, cultural attitudes, and social networks (Bandiera and Rasul 2006; Munasib and Jordan 2011; Staal et al. 2002; Storm et al. 2015). New knowledge acquired through technology training can also be passed on through neighbors and friends (Nakano et al. 2018; Pratiwi and Suzuki 2020; Ryan 2009). However, to the best of our knowledge, none of the previous studies have examined the neighborhood effect under a performance-based environmental program, nor the interaction of different types of neighborhood effects. 
In this paper, we take a general approach towards modeling the BMP adoption decision under a performance-based environmental program and investigate two types of neighborhood effects: a knowledge spillover and an environmental outcome externality among neighboring farms. These two effects and their interactions could lower an individual farmer's implicit adoption cost and increase the productivity of participation in performancebased programs, thus increasing participation rates and the cost-effectiveness of such programs. We focus on the interactions among neighboring farmers and these local spillovers' translation to a global effect. As LeSage (2014) explained for spatial econometric models, the crucial difference between local spillover and global spillover is the endogeneity of feedback. Endogenous interactions can lead to a sequence of adjustments in all regions where a new long-run steady state equilibrium might arise. In our model, the global level outcome is driven by heterogeneous interactions at local scales and their spatial spillovers.

Focusing on interactions between local and global levels has led investigators toward tools that allow the equilibrium to emerge through simulation rather than being imposed as the closure of a mathematical model (Matthews et al. 2007). Agent-based modeling (ABM) simulation has become a tool of choice for this reason and others. Filatova et al. (2013) note that an ABM approach allows the modeler to use representations of individuals that "act more realistically, accounting for bounded rationality, heterogeneity, interactions, evolutionary learning and out-of-equilibrium dynamics, and to combine this representation with a dynamic heterogenous representation of the spatial environment." This bottom-up approach lets equilibria emerge from agents' actions as they follow decision rules within a social context-in contrast to assuming or imposing the equilibrium outcome (Bonabeau 2002). Agents can be specified to follow decision rules similar to observed conditions (Wiesbuch 2000; Wiesbuch and Boudjema 1999), and policy-relevant features of equilibration can also be observed in addition to the outcome; for example, the time it takes to reach the desired outcome (Chen et al. 2012). Moreover, the technique can account for spatial heterogeneity and allow agents to interact with socio-ecological features, as has been applied in the innovation diffusion literature generally (Kiesling et al. 2012; Zhang and Vorobeychik 2019) and in modeling technology diffusion in terms of farmers' expectation of costs and returns facing risks (Berger 2001; Schwarz and Ernst 2009), as well as linking to hydrologic-agronomic models to study the impacts of agricultural conservation practices on water quality (Daloglu et al. 2014; Ng et al. 2011).

Our model takes advantage of these ABM features to simulate various communities with heterogenous spatial features and various distributions of farmer types, using parameters derived from empirical studies, and a network topology (both von Neumann and Moore neighborhoods) at the meso level of neighborhood influence, providing a stylized framework that can be extended to represent more complex systems. Our model is in the 
category that Zhang and Vorobeychik (2019) describe as "learning tools," affecting policy decisions at a conceptual level rather than making direct predictions. We place less focus on influencers and instead on a network structure that has far more local connections, creating results that depend on the distribution of farmer types and allows us to look for the cost-effective policies targeting those community features.

Our paper thus contributes to this literature by modeling the relationship between farmers' interactions and the aggregate outcomes linked through the knowledge spillover and environmental externalities affected by farmers' heterogeneous innate interests in conservation program participation. We explore both spatial and dynamic features of the emergent outcomes in the system along with effects of heterogeneity in farmers' attitudes towards new programs and their fields' characteristics. To focus on these aspects of the model, we assume farmers are price takers who observe the exogenous market price of a performance-based program for nutrient reduction. We do not model price change in this paper because we are considering communities that are a small portion of the program; this feature can be adjusted in future applications to represent the reality that credit prices can change over time as determined by market supply and demand. One important feature of the model is that it allows farmers' profits from participating in the performance-based programs to be interdependent with their neighbors' actions through spillover effects. Because of this feature, a farmer's profit is difficult to anticipate, and we model these farmers as backward-looking adaptive profit-seekers rather than forward-looking profitmaximizers. We show that knowledge spillover effects and positive environmental externalities increase participation in conservation programs and provide an innovative framework that highlights the potential effectiveness of policies such as educational campaigns. This can broaden the policy maker's toolbox and increase the cost-effectiveness of performancebased programs.

\section{Method and Model Setup}

\section{Method}

We use an ABM approach to study the effects of individual farmers' decisionmaking process and the resulting emergent phenomena (Epstein 1999). Each agent individually assesses its situation and makes decisions to improve its payoff based on its own set of rules while being affected by other agents' decisions as well. There are two sources of interactions: a knowledge spillover and an environmental outcome externality. The knowledge spillover is represented by reducing part of the transaction cost of participating in performance-based environmental payment program. The environmental outcome externality is represented by improving the performance of 
participation and thus improving the payoff. We also study the costeffectiveness of various policy interventions on heterogenous communities. The model is implemented in NetLogo (Wilensky 1999; Tisue and Wilensky 2004), a widely used platform for ABM work (Kravari and Bassiliades 2015).

\section{Model Setup}

We model a generic BMP adoption decision set in a generic performance-based nutrient reduction payment program. We start by simulating a watershed landscape of farms with heterogeneous soil productivity indicator $s(0<s<$ 1) where $s$ is the normalized indicator for the productivity of the farm field for this BMP. This indicator represents BMP productivity or the nutrient reduction performance of adopting the BMP. Higher $s$ represents higher productivity or reduction performance and thus higher payoff for participating in the performance-based programs. Such indicators can be derived from a hydrologic model such as SWAT or APEX that take into account physical characteristics including soil type and location, agricultural decisions including BMP adoption and fertilizing timing, and climate information such as rainfall. Each cell in our model represents one decisionmaking farmer with a farm field. We first randomly draw the soil productivity indices from a uniform distribution then smooth this landscape, making adjacent fields more similar to each other and reducing discontinuity, which is often the case in real landscapes. This also reflects the historical environmental outcome externality, where high/low runoff fields tend to increase/decrease the runoff of the adjacent fields (e.g., USDA NRCS soils, FAO of the UN). Figure 1 provides one example of such landscape of soil productivity indices, where the brighter cells correspond to higher $s$.

We consider a generic BMP that reduces nutrient runoff and improves the receiving waterbody's water quality. Farmer $i$ at time period $t$ who adopts this BMP has $x_{i, t}$ of 1 (and 0 otherwise), indicating that they participate in the

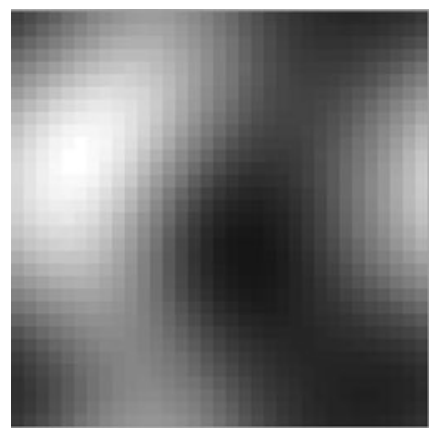

Figure 1. Example of Simulated Landscape 
performance-based payment program and get a payoff corresponding to their nutrient reduction outcome $R\left(s_{i}, s_{j}, x_{i, t}, \boldsymbol{x}_{j, t}\right)$, which also depends on their neighbors' participation through the binary vector $\boldsymbol{x}_{j, t}$ representing all neighbors' participation. The model setup thus captures the literature's established fact that BMPs do not generally provide enough private benefit for farmers to adopt them, leading to low participation in performance-based programs.

There are costs to getting to know how the program works-getting certified and monitored, learning how to adopt the BMP, and more. We assume this transaction cost has two parts, a one-time cost $\left(y_{i, t}\right)$ when trying the BMP and participating in the program for the first time and an annual cost $\left(c_{\mathrm{a}}\right)$ for machinery, labor, paperwork, and other such recurring costs. In addition, farmers have a willingness to adopt $\left(w_{i}\right)$ that reflects different attitudes towards new BMP technology and participating in government programs. Borrowing from Schwarz and Ernst (2009), we assume there are three types of farmers, which we call social leader or innovator $\left(w_{h}\right)$, mainstream $\left(w_{m}\right)$, and traditional $\left(w_{l}\right)$ types.

As described above, we do not impose rational profit maximization or forward-looking ability on the farmers in our ABM. Farmers make decisions year by year while observing their own results, possibly learning from their neighbors, and being affected by their neighbors' decisions. Farmers first consider adopting the BMP, comparing their willingness-to-pay to participate with the transaction cost, and then after a year of doing so they calculate their profit from the program to see if it has improved compared to the previous year,

$$
\begin{gathered}
V_{i, t}\left(x_{i, t}, x_{j, t} s_{i}\right)=\left(p_{R} * R\left(s_{i}, s_{j}, x_{i, t}, x_{j, t}\right)-y_{i, t}-c_{a}\right) * x_{i, t} \\
x_{i, t}=1 \text { if } w_{i} \geq y_{i, t}+c_{a}
\end{gathered}
$$

where $p_{R}$ is the price for a nutrient reduction credit. We have located farmers on a two-dimensional planar grid, so each farmer $i$ has four neighbors from whom they can learn and whose BMP adoption decisions also affect $i$ 's performance. We test a wider neighborhood definition below.

\section{Positive Spillover Effects}

There are two positive spillover effects between each farm and its neighbors. One is the knowledge spillover effect, which is represented in the one-time information cost part of the transaction cost,

$$
y_{i, t}=c_{I}-\theta * I_{j, t-1}
$$

for the first time participating and 0 in any later year. $I_{j, t-1}=1$ if at least one of the neighbors has participated in the program prior to year $t$ (and 0 otherwise). 
This captures the learning from experienced neighbors that reduces the information cost, thus lowering the hurdle to participate. The parameter $c_{I}>$ 0 is the representative information cost, and $\theta>0$ is the information sharing coefficient.

The other externality is the environmental outcome externality from neighbors' adoption of BMP and is represented by the nutrient reduction outcome function

$$
R\left(s_{i}, s_{j}, x_{i, t} x_{j, t}\right)=\alpha+\beta s_{i}+\gamma \sum_{J=1}^{4} s_{j} * x_{j, t}
$$

where $\alpha, \beta$, and $\gamma$ are positive parameters. Higher soil productivity leads to higher nutrient reduction and the positive externality from neighbors can be additive through $\gamma$, the conservation spillover coefficient, increasing the performance. This environmental outcome externality provides an incentive for farmers to share their knowledge to make it easier for their neighbors to participate.

The hypotheses that we investigate with this model are:

1) Communities with a higher percentage of innovators will result in a higher participation rate, and in a non-linear fashion.

2) Communities with a higher percentage of innovators will arrive at the equilibrium faster.

3) Communities with a higher percentage of high-productivity land will result in higher participation rate.

4) Communities with a higher percentage of "traditionals" can create regions where no one participates in the program.

\section{Analytical Baselines}

Before presenting the simulation results, we derive some mathematical relationships. The first component of a farmer's decision to adopt the BMP and participate in the performance-based payment program is the interaction between their WTP to participate and the participation cost. Combining Eq. [2] and Eq. [3], the farmer will participate (set $x_{i, t}=1$ ) if $w_{i} \geq c_{a}+c_{I}-\theta^{*} I_{j, t-1}$. We start at $t=0$ with no participation to simulate the beginning of a payment program, so in the first year that constraint becomes $w_{i} \geq c_{a}+c_{I}$. This is thus the lower bound on WTP to get participation started. Once at least one of farmer $i$ 's neighbors have adopted, the farmer's necessary WTP 
becomes $w_{\mathrm{i}} \geq c_{a}+c_{I}-\theta$, as $i$ benefits from the knowledge spillover effect. Individuals with $w_{i}<c_{a}+c_{I}-\theta$, or $w_{i}<c_{a}+c_{I}$ without any participating neighbors will never participate, which explains why in reality there are areas where no one participates.

Farmers also condition their adoption with the goal of increasing profits as described in the profitability Eq. [1] and the nutrient reduction Eq. [4], where the latter captures the external effects of nutrient reduction by neighbors $j=$ 1 to 4 on farmer $i$ 's profit. After participation at $t$, farmer $i$ observes their realized return $p_{\mathrm{R}}{ }^{*} R\left(s_{\mathrm{j}} s_{j}, \boldsymbol{x}_{i, t}, x_{j, t}\right)$, henceforth simply $p_{R} R_{i, t}$, and use this to determine whether to participate in the next period, thus setting $x_{i, t+1}$ before the beginning of period $t+1$. Because choosing not to participate results in a return of zero-farmer $i$ receives no payment at no cost if they don't adopt the BMP-Eq. [1] and [2] combine with Eq. [3] to form the condition $p_{\mathrm{R}} R_{\mathrm{i}, \mathrm{t}} \geq$ $c_{\mathrm{a}}+c_{\mathrm{I}}-\theta^{*} I_{\mathrm{j}, \mathrm{t}-1}$ for farmer $i$ to participate at time $t+1\left(\right.$ set $\left.x_{i, t+1}=1\right)$

Because farmers in our simulation do not initially participate, $V_{i, 0}=0$. At the beginning of $t=1$ anyone who decided to participate had $w_{\mathrm{i}} \geq c_{\mathrm{a}}+c_{\mathrm{I}}$, but now at the end of $t=1$ they are considering whether $p_{R} R_{i, t} \geq c_{a}+c_{I}$ to determine whether to participate in period $t=2$. (Note that $\mathrm{I}_{\mathrm{j}, t-1}$ is 0 for all farmers at $t=1$.)

From $t=2$ forward, any farmer who has participated in period $t$ falls into one of the following four cases.

1) If farmer $i$ participated at $t$ for the first time, then the condition to participate at $t+1$ becomes $p_{R} R_{i, t} \geq c_{a}+c_{I}-\theta^{*} I_{j, t-1}$

2) If farmer $i$ didn't participate at $t-1$ and participated at $t$ but the farmer has participated before $t-1$, there is no information cost, so we have $p_{R} R_{i \text {, }}$ $t \geq c_{a}$

3) If farmer $i$ participated at $t-1$ for the first time and also participated at $t$, then to continue participating in $t+1$, the return needs to be higher:

$$
p_{R} R_{i, t}-c_{a} \geq p_{R} R_{i, t-1}-c_{I}+\theta * I_{j, t-2}-c_{a}
$$

Recall Eq. [4] and the soil productivity doesn't change, so this case is equivalent to:

$$
\left.\gamma S_{j} *\left(\sum_{j=1}^{4} x_{j, t}-\sum_{j=1}^{4} x_{j, t-1}\right) \geq-c_{I}+\theta * I_{j, t-2}\right)
$$


If farmer $i$ participated at $t-1$ and $t$ and has participated at any time before $t$ -1 , the derivation follows Case 3 except that the information cost is zero in both periods, so the condition becomes:

$$
\sum_{j=1}^{4} x_{j, t}-\sum_{j=1}^{4} x_{j, t-1} \geq 0
$$

That is, the number of BMP-adoptiing neighbors did not decrease from $t-1$ to $t$.

\section{Parameterization and Simulation Results}

\section{Parameterization}

We set the initial parameters based on data from Duke et al. (2020). Information for 196 fields located on the Eastern Shore of Maryland was collected and processed through Maryland's Nutrient Trading Tool (MDNTT) to predict their participation in the Maryland water quality trading (MWQT) program. We set our parameters to match the productivity information and associated costs for these fields. The unit price for nutrient reduction is $p_{R}$, ranging from $\$ 20$ to $\$ 100$ per pound of phosphorus (P) reduction. We assume the information cost $y_{i, t}$ to be between $\$ 0$ and $\$ 30 / \mathrm{lb} /$ year, representing a range of complexity and length of WQT contracts (DeBoe and Stephenson 2016).The adoption cost of a BMP per year $\left(c_{a}\right)$ ranges between $\$ 10$ to $\$ 250$ per acre per year. The productivity of BMP adoption in the sample ranges from 1 to $8 \mathrm{lbs}$ per acre in terms of phosphorus reduction. We set the information sharing cost $\theta$ to be half of the information cost. Table 1 summarizes the model's parameters.

Table 1. Parameters and Descriptions

\begin{tabular}{lllc}
\hline Parameter & Unit & Description & Initial value \\
\hline$p_{R}$ & \$/lb of P reduction & Unit price for nutrient reduction & 60 \\
$c_{I}$ & \$/acre & One-time information cost & 15 \\
$\theta$ & \$/acre & Information sharing coefficient & 7.5 \\
$c_{a}$ & \$/acre & Yearly adoption cost of BMP & 60 \\
$\alpha$ & lb/acre & Productivity parameter & 1 \\
$\beta$ & lb/acre & Productivity parameter & 4 \\
$\gamma$ & lb/acre & Conservation spillover coefficient & 1 \\
$w_{h}$ & \$/acre & WTP for innovator & 80 \\
$w_{m}$ & \$/acre & WTP for mainstream & 70 \\
$w_{l}$ & \$/acre & WTP for traditional & 60 \\
\hline
\end{tabular}




\section{Simulation Results}

We simulate a 33 by 33 landscape, which has 1089 fields. The following figures show an example run. Figure 2 shows the landscape and soil qualities and the farmers' WTP values (randomly distributed among the grid). Figure 3 shows the process of BMP adoption arriving at a steady state equilibrium in the landscape and community of Figure 2.

To test hypotheses 1 and 2, we fix the percentage of traditional types and run through varying percentages of the mainstream and social leader types. In the plots of Figure 4, each line represents the evolution of a different type of community, averaged over 30 simulations, with the number of years on the horizontal axis. The panels from left to right have $30 \%, 40 \%$, and $50 \%$ of the farmers classified as traditional. The lines in each graph vary from blue to red as we increase the representation of social leaders from $2 \%$ to $20 \%$ in steps of 2 percentage points. The blue lines thus are also those lowest and to the right in the diagram and the red lines the highest and to the left.

Next we fix the percentage of the mainstream types in the community and consider varying levels of the traditional and social leader types in each simulation. Figure 5 shows, from left to right, 30\%, 40\%, and $50 \%$ of farmers set to the mainstream type. Each line again shows an average across 30 simulations ranging from $2 \%$ (blue, bottom right) to $20 \%$ (red, top left) innovators.

These simulation results support hypotheses 1 and 2: Communities with a higher percentage of innovators result in higher participation and arrive at such steady states faster. The non-linear nature of that relationship is apparent in Figures 4 and 5, as well as in Figure 6 where we group the mainstream and traditional types as "non-innovators".

Because there are many possible topologies of agent connectivity other than the one we are investigating, we also considered farms on the same twodimensional layout but with a larger number of neighbors who can be

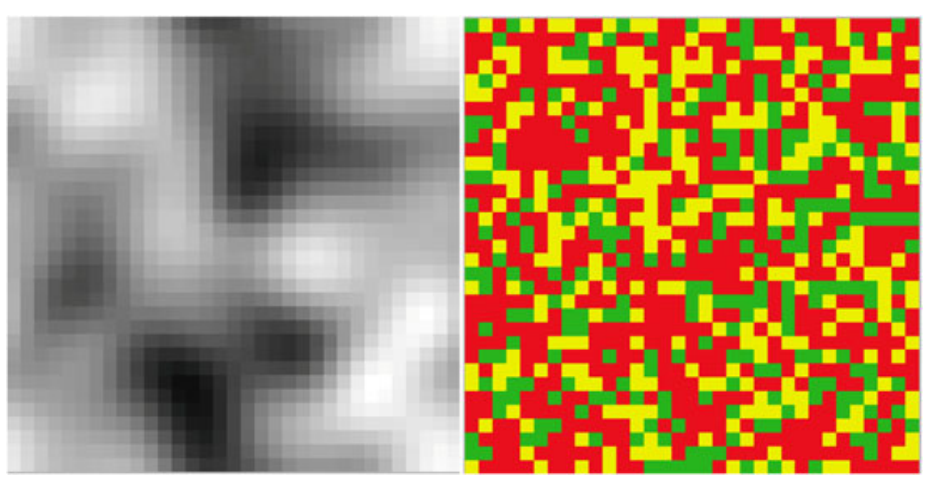

Figure 2. Example Landscape: Soil Productivity (left) and Farmer Types (right). Green: social Leader; Red: Mainstream; Yellow: Traditional 


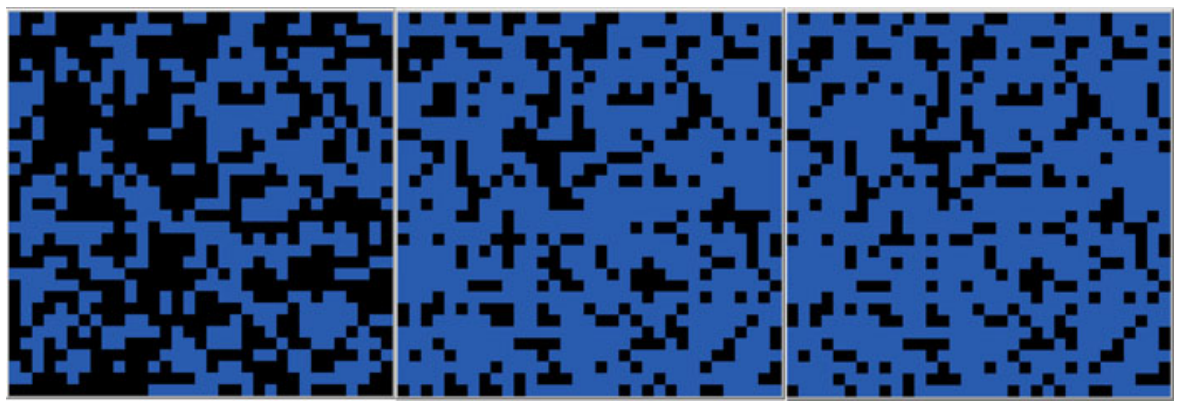

Figure 3. Participation Process in the Landscape, with Time Moving from Left to Right. Black: Nonparticipants; Blue: Participants

information sources and spreaders of the environmental externality for the focal farm. We explained in above that we have thus far treated farm i's neighbors as those to the North, South, East, and West of $i$ (a von Neumann neighborhood). To investigate one other possible topology, we increased the neighbors to 8 by additionally including those to i's Northeast, Southeast, Southwest, and Northwest (a Moore neighborhood). The results are similar to what we have shown above, and as a comparison to Figure 5's four neighbors to farmer $i$ we show the results in Figure 7 for eight neighbors to $i$. We can see that the steady-state results and speed to reach them are generally higher and faster-because farmers with eight neighbors can learn from more possible sources. We thus have further support of our results, although an in-depth exploration of other topologies is beyond the scope of this paper.

To test our third hypothesis, we fix the percentage of farmer types and test different distributions of soil productivity. In Figure 8 we observe no evidence to support this hypothesis (the curves with differing soil productivity overlap each other), which is counterintuitive. It appears that with these parameter settings, the farmer type drives adoption dynamics more than the soil productivity does. This is consistent with previous findings in which farmers' perceived efficacy is the most important determent of their BMP adoption decisions (Zhang et al. 2016), but future research is needed to explore the mechanism behind this result.

The last hypothesis can be shown in an example steady-state adoption map as in Figure 9, where we observe blocks of black (non-adopter) areas. Without enough neighbors participating (blue), there is not enough incentive for participants who are not innovators.

\section{Policy Implications}

Our results suggest two ways to use educational campaigns to increase participation in and attitudes towards performance-based payment programs: 

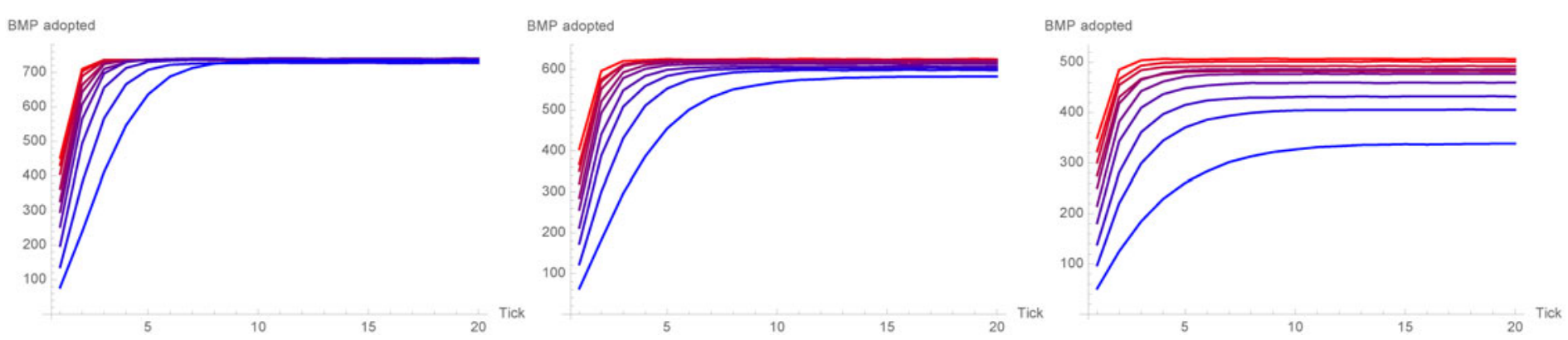

Figure 4. Adoption Process, Fixing the Percentage of Traditional Types

BMP adopted

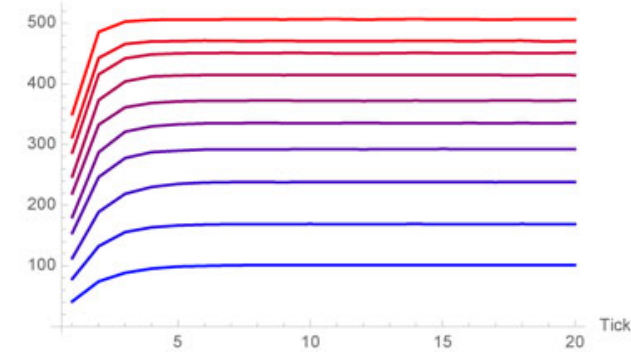

BMP adopted

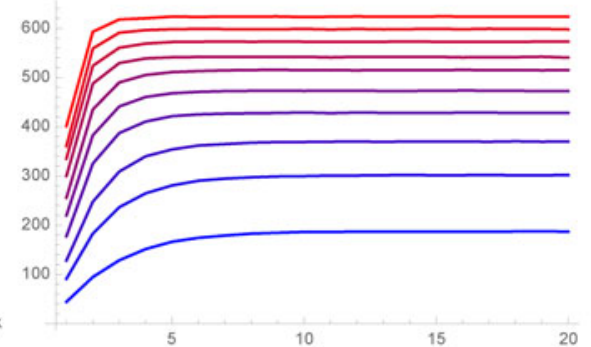

BMP adopted

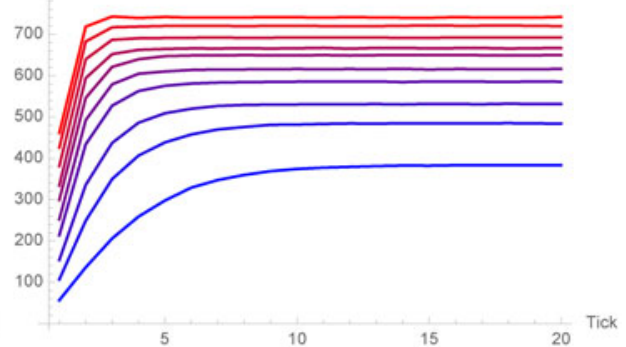

Figure 5. Adoption Process, Fixing the Percentage of Mainstream Types 


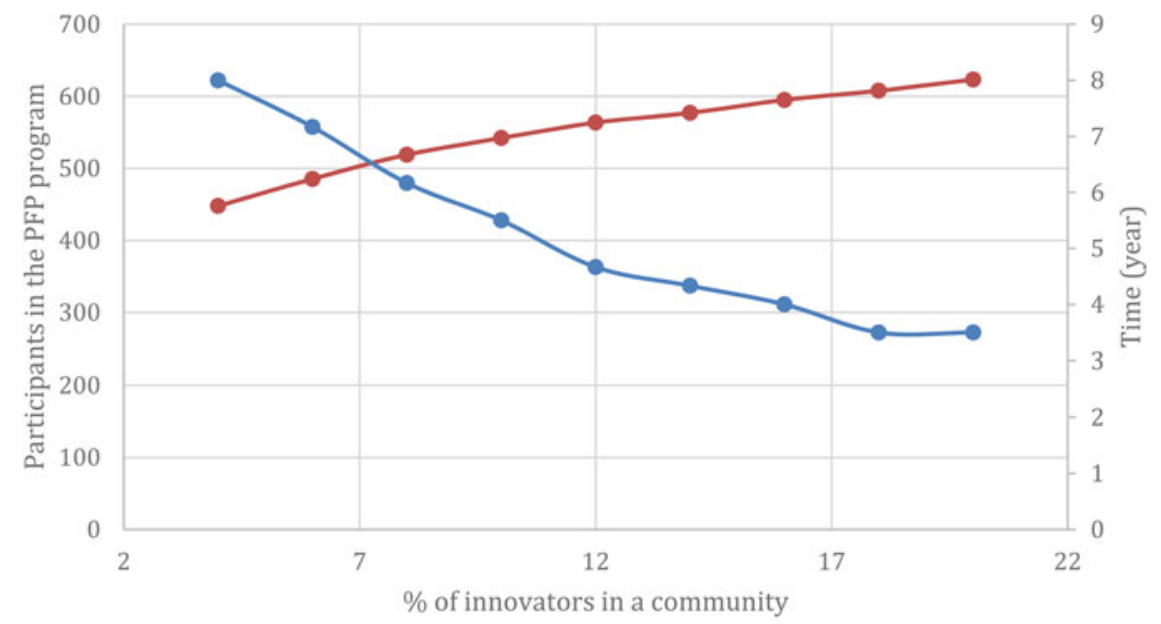

$\multimap$ BMP adoptors $\longrightarrow$ Time to equilibrium (years)

Figure 6. Number of Participats and Time to Arrive at Steady State Given \% of Innovators in a Community

1) reducing the initial information costs for first-time participants, and/or 2) increasing farmers' WTP to participate by helping them see the potential benefits of payment programs not only for themselves but for the community in general. Benefits of these educational campaigns can then be multiplied by the environmental outcome externality through the global spillover effect. We address the first case in Section 2.4 by showing that farmers with middle or low level of WTP are more likely to begin participation and those who participated are also more likely to continue.

For the second situation, we examine the simulation results from varying levels of types of farmers. For example, when the social leaders (innovators) are fixed at $10 \%$, increasing the representation of mainstream types from $30 \%$ to $32 \%$ means motivating $2 \%$ of traditionals to act like mainstream types. If we make the assumption that the average cost to change a person from traditional $(\mathrm{WTP}=60)$ to mainstream $(\mathrm{WTP}=70)$ or from mainstream to social leader ( $\mathrm{WTP}=80$ ) is $\$ 10$, and from traditional to social leader is $\$ 20$, we find the relationships shown in Figure 10. The vertical axis is calculated using the total program costs divided by the number of increased participants. The resulting cost differences are mostly driven by the difference in the underlying WTPs ( $\$ 10$ and $\$ 20)$, but it also depends on the composition of communities, which can be seen clearly in the curve that shows payments to convert mainstream types to innovators.

We acknowledge this analysis is most likely underestimating the conversion cost of farmer types, but the results have significant policy implications in terms of choosing communities in which to intervene. First of all, regardless of the 


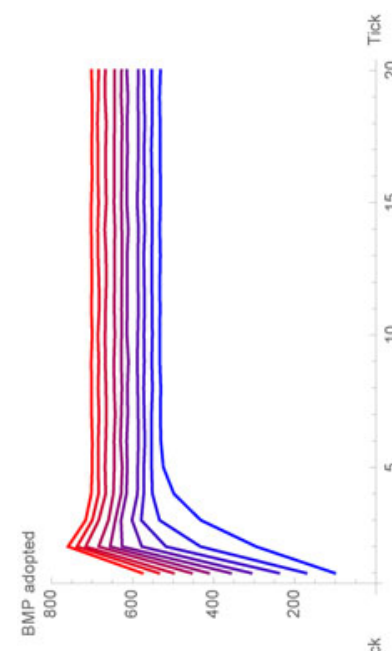



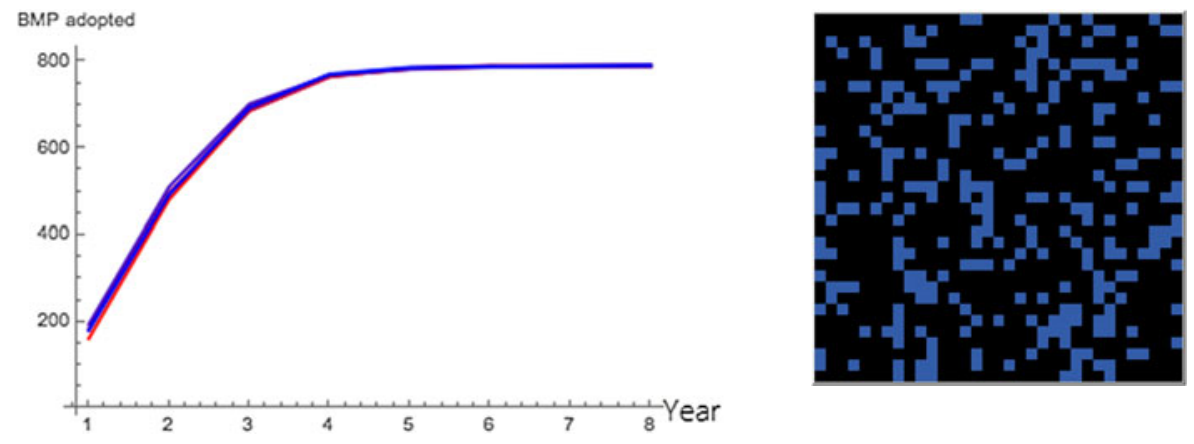

Figure 9. Example of Steady

Figure 8. Participation Process with Varying State Adoption Map Soil Productivity Distributions

composition of the communities, it is always more cost-effective to use an education campaign or subsidy program that targets the traditional rather than mainstream types. The mainstream farmers may participate in payment programs when enough neighbors are doing so, but traditional farmers will not do so without such programs to help motivate them. Secondly, it is more cost-effective to motivate participation when the community has a low percentage of innovators. In communities like this, motivating people on the margin will benefit their neighbors and their neighbors' neighbors through the global spillover effect. Thirdly, it is more cost-effective to convert more traditionals with a lower payment to mainstream, rather than paying each traditional more to convert them to innovators.

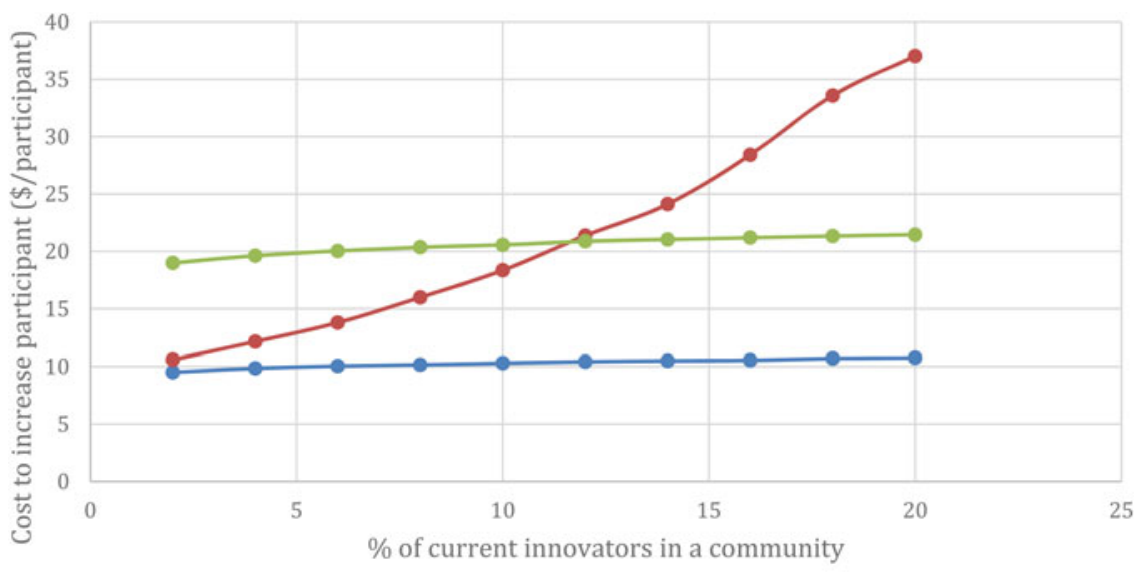

$\rightarrow$ traditional to mainstream $\rightarrow$ mainstream to innovators

Figure 10. Policy costs per new participant 


\section{Discussion and conclusion}

A knowledge spillover creates positive externalities among neighbors as farmers share information and reduce transaction costs. An environmental outcome positive externality enhances the return on the spillover, leveraging the improvements in soil health and water quality. We use an ABM approach to examine the interactions between these two effects in agricultural decisions under a generic performance-based payment program. We show that farmers' attitudes towards participation play a more important role than their soil productivities in our calibrated model, and this supports the use of educational campaigns to increase farmers' awareness of the environmental benefits and promote participation. Because communities with a higher percentage of innovators have greater adoption and faster adoption rates, these social leaders play an important and non-linear role in the diffusion of BMP adoption.

We also investigate the policy effects of this emergent outcome. With a model calibrated to parameter values that we would expect to see in typical communities, we find that spending on education is better targeted to a group of "traditionals" who are less likely to have internalized the community's benefits. This is counterintuitive from the perspective of the usual triage approach where the focus would be on the "mainstream" individuals-those at at the margin. Our results arise from the interaction of the two spillover effects: mainstream types can benefit from the "role models" of their innovator neighbors without intervention, while traditional types left alone create their own follow-on effects of non-adoption; the benefit of the change in community composition is then magnified through a global spillover effect, leading to more desirable outcomes. This argument for educational campaigns that target communities with a lower percentage of social leaders, and within those communities target the most non-innovative types, provides policy insights to increase the cost-effectiveness of performance-based programs.

This stylized framework can be applied to simulate various scenarios. Future research can, for example, expand the model setup or use different parameterizations to explore the role of social norms that may be influenced by non-economic reasoning, the dynamics of soil productivity in linkages to soil management decisions, and identify the most cost-effective targeted policies.

\section{Acknowledgments}

The authors would like to thank the editors and two anonymous referees for their insightful and detailed suggestions, which have helped to improve this article immensely. 


\section{References}

Baerenklau, K.A. 2005. "Toward an Understanding of Technology Adoption: Risk, Learning, and Neighborhood Effects." Land Economics 81(1): 1-19.

Bandiera, O., and I. Rasul. 2006. "Social Networks and Technology Adoption in Northern Mozambique." The Economic Journal 116(514): 869-902.

Berger, T. 2001. "Agent-Based Spatial Models Applied to Agriculture: A Simulation Tool for Technology Diffusion, Resource Use Changes and Policy Analysis." Agricultural Economics 25(2-3): 245-260.

Bergtold, J.S., P.A. Duffy, D. Hite, and R.L. Raper. 2012. “Demographic and Management Factors Affecting the Adoption and Perceived Yield Benefit of Winter Cover Crops in the Southeast." Journal of Agricultural and Applied Economics 44(1): 99-116.

Bonabeau, E. 2002. "Agent-Based Modeling: Methods and Techniques for Simulating Human Systems." Proceedings of the National Academy of Sciences 99(suppl 3): 7280-7287.

Breetz, H.L., K. Fisher-Vanden, H. Jacobs, and C. Schary. 2005. "Trust and Communication: Mechanisms for Increasing Farmers' Participation in Water Quality Trading." Land Economics 81(2): 170-190.

Carlisle, L. 2016. "Factors Influencing Farmer Adoption of Soil Health Practices in the United States: A Narrative Review." Agroecology and Sustainable Food Systems 40(6): 583-613.

Case, A. 1992. "Neighborhood Influence and Technological Change." Regional Science and Urban Economics 22(3): 491-508.

Chen, X., F. Lupi, A. Li, R. Sheely, A. Vina, and J. Liu. 2012. "Agent-Based Modeling of the Effects of Social Norms on Enrollment in Payments for Ecosystem Services." Ecological Modelling 229: 16-24.

Claassen, R.L, and M. Weinberg. 2006. Rewarding Farm Practices versus Environmental Performance (EB-5). USDA Economic Research Service.

Daloğlu, I., J.I. Nassauer, R.L. Riolo, and D. Scavia. 2014. “Development of a Farmer Typology of Agricultural Conservation Behavior in the American Corn Belt." Agricultural Systems 129: 93-102.

Davey, K.A., and W.H. Furtan. 2008. "Factors That Affect the Adoption Decision of Conservation Tillage in the Prairie Region of Canada." Canadian Journal of Agricultural Economics/Revue Canadienne d'agroeconomie 56(3): 257-275.

DeBoe, G., and K. Stephenson. 2016. "Transactions Costs of Expanding Nutrient Trading to Agricultural Working Lands: A Virginia Case Study." Ecological Economics 130: 176-185.

Druschke, C.G., and S. Secchi. 2014. "The Impact of Gender on Agricultural Conservation Knowledge and Attitudes in an Iowa Watershed." Journal of Soil and Water Conservation 69(2): 95-106.

Duke, J., H. Liu, T. Monteith, J. McGrath, and N. Fiorellino. 2020. "A Method for Predicting Participation in a Performance-Based Water Quality Trading Program." Ecological Economics 177. https://doi.org/10.1016/j.ecolecon.2020.106762.

EPA/NPDES. Available at https://www.epa.gov/npdes/water-quality-trading (accessed July 2019).

Epstein, J.M. 1999. "Agent-Based Computational Models and Generative Social Science." Complexity 4(5): 41-60.

Fales, M., R. Dell, M.E. Herbert, S.P. Sowa, J. Asher, G. O’Neil, P.J. Doran, and B. Wickerham. 2016. "Making the Leap from Science to Implementation: Strategic Agricultural Conservation in Michigan's Saginaw Bay Watershed." Journal of Great Lakes Research 42(6): 1372-1385.

Filatova, T., P.H. Verburg, D.C. Parker, and C.A. Stannard. 2013. "Spatial Agent-Based Models for Socio-Ecological Systems: Challenges and Prospects." Environmental Modelling \& Software 45: 1-7.

Hanson, J.C., and K.E. McConnell. 2008. “Simulated Trading for Maryland's Nitrogen Loadings in the Chesapeake Bay." Agricultural and Resource Economics Review 37(2): 211-26. https://doi.org/10.1017/S1068280500003014. 
Holloway, G., D. Lacombe, and J.P. LeSage. 2007. "Spatial Econometric Issues for Bio-Economic and Land-Use Modelling." Journal of Agricultural Economics 58(3): 549-588.

Kiesling, E., M. Günther, C. Stummer, and L.M. Wakolbinger. 2012. "Agent-Based Simulation of Innovation Diffusion: A Review." Central European Journal of Operations Research 20(2): 183-230.

Kravari, K., and N. Bassiliades. 2015. "A Survey of Agent Platforms." Journal of Artificial Societies and Social Simulation 18(1): 11.

Läpple, D., G. Holloway, D.J. Lacombe, and C. O’Donoghue. 2017. "Sustainable Technology Adoption: A Spatial Analysis of the Irish Dairy Sector." European Review of Agricultural Economics 44(5): 810-835.

Lemke, A.M., T.T. Lindenbaum, W.L. Perry, M.E. Herbert, T.H. Tear, and J.R. Herkert. 2010. "Effects of Outreach on the Awareness and Adoption of Conservation Practices by Farmers in Two Agricultural Watersheds of the Mackinaw River, Illinois." Journal of Soil and Water Conservation 65(5): 304-315.

LeSage, J.P. 2014. "What Regional Scientists Need to Know about Spatial Econometrics." Available at SSRN 2420725.

Lewis, D.J., B.L. Barham, and B. Robinson. 2011. "Are There Spatial Spillovers in the Adoption of Clean Technology? The Case of Organic Dairy Farming." Land Economics 87(2): 250-267.

Mariola, M.J. 2012. "Farmers, Trust, and the Market Solution to Water Pollution: The Role of Social Embeddedness in Water Quality Trading." Journal of Rural Studies 28(4): 577-589.

Matthews, R.B., N.G. Gilbert, A. Roach, J.G. Polhill, and N.M. Gotts. 2007. "Agent-Based LandUse Models: A Review of Applications." Landscape Ecology 22(10): 1447-1459.

Miyata, S., and J. Manatunge. 2004. "Knowledge Sharing and Other Decision Factors Influencing Adoption of Aquaculture in Indonesia." International Journal of Water Resources Development 20(4): 523-536.

Muenich, R.L., M.M. Kalcic, J. Winsten, K. Fisher, M. Day, G. O'Neil, Y.-C. Wang, and D. Scavia. 2017. "Pay-for-Performance Conservation Using SWAT Highlights Need for Field-Level Agricultural Conservation." Transactions of the ASABE 60(6): 1925-1937.

Munasib, A., and J.L. Jordan. 2011. "The Effect of Social Capital on the Choice to Use Sustainable Agricultural Practices." Journal of Agricultural and Applied Economics 43 (1379-2016-113720): 213-227.

Nakano, Y., T.W. Tsusaka, T. Aida, and V.O. Pede. 2018. "Is Farmer-to-Farmer Extension Effective? The Impact of Training on Technology Adoption and Rice Farming Productivity in Tanzania." World Development 105: 336-351.

Newburn, D.A., and R.T. Woodward. 2012. "An Ex Post Evaluation of Ohio's Great Miami Water Quality Trading Program 1." JAWRA Journal of the American Water Resources Association 48(1): 156-169.

Ng, T.L., J.W. Eheart, X. Cai, and J.B. Braden. 2011. "An Agent-Based Model of Farmer DecisionMaking and Water Quality Impacts at the Watershed Scale under Markets for Carbon Allowances and a Second-Generation Biofuel Crop." Water Resources Research 47(9).

Nguyen, N.P., J.S. Shortle, P M. Reed, and T.T. Nguyen. 2013. "Water Quality Trading with Asymmetric Information, Uncertainty and Transaction Costs: A Stochastic Agent-Based Simulation." Resource and Energy Economics 35(1): 60-90.

NOAA (2019) HAB. Available at https://oceanservice.noaa.gov/hazards/hab/ (accessed July 2019)

Palm-Forster, L.H., S.M. Swinton, F. Lupi, and R.S. Shupp. 2016a. "Too Burdensome to Bid: Transaction Costs and Pay-for-Performance Conservation." American Journal of Agricultural Economics 98(5): 1314-1333.

Palm-Forster, L.H., S.M. Swinton, T.M. Redder, J.V. DePinto, and C.M.W. Boles. 2016b. "Using Conservation Auctions Informed by Environmental Performance Models to Reduce Agricultural Nutrient Flows into Lake Erie." Journal of Great Lakes Research 42(6): 1357-1371.

Peterson, J.M., C.M. Smith, J.C. Leatherman, N.P. Hendricks, and J.A. Fox. 2015. "Transaction Costs in Payment for Environmental Service Contracts." American Journal of Agricultural Economics 97(1): 219-238. 
Pratiwi, A., and A. Suzuki. 2020. "Does Training Location Matter? Evidence from a Randomized Field Experiment in Rural Indonesia." Agricultural and Food Economics 8 (1): 1-23.

Reimer, A.P., and L.S. Prokopy. 2014. "Farmer Participation in US Farm Bill Conservation Programs." Environmental Management 53(2): 318-332.

Reimer, A.P., A.W. Thompson, and L.S. Prokopy. 2012. "The Multi-Dimensional Nature of Environmental Attitudes among Farmers in Indiana: Implications for Conservation Adoption." Agriculture and Human Values 29(1): 29-40.

Rolfe, J., and D. Gregg. 2015. "Factors Affecting Adoption of Improved Management Practices in the Pastoral Industry in Great Barrier Reef Catchments." Journal of Environmental Management 157: 182-193.

Ryan, C.M. 2009. "Managing Nonpoint Source Pollution in Western Washington: Landowner Learning Methods and Motivations." Environmental Management 43(6): 1122-1130.

Ryan, R.L., D.L. Erickson, and R. De Young. 2003. "Farmers' Motivations for Adopting Conservation Practices along Riparian Zones in a Mid-Western Agricultural Watershed." Journal of Environmental Planning and Management 46(1): 19-37.

Schwarz, N. and A. Ernst. 2009. "Agent-Based Modeling of the Diffusion of Environmental Innovations-An Empirical Approach." Technological Forecasting and Social Change 76 (4): 497-511.

Soule, M.J., A. Tegene, and K.D. Wiebe. 2000. "Land Tenure and the Adoption of Conservation Practices." American Journal of Agricultural Economics 82(4): 993-1005.

Staal, S.J., I. Baltenweck, M.M. Waithaka, T. DeWolff, and L. Njoroge. 2002. "Location and Uptake: Integrated Household and GIS Analysis of Technology Adoption and Land Use, with Application to Smallholder Dairy Farms in Kenya." Agricultural Economics 27(3): 295-315.

Stephenson, K., and L. Shabman. 2017. "Can Water Quality Trading Fix the Agricultural Nonpoint Source Problem?” Annual Review of Resource Economics 9: 95-116.

Storm, H., K. Mittenzwei, and T. Heckelei. 2015. "Direct Payments, Spatial Competition, and Farm Survival in Norway." American Journal of Agricultural Economics 97(4): 1192-1205.

Tisue, S., and U. Wilensky. 2004. "NetLogo: Design and Implementation of a Multi-Agent Modeling Environment." In Proceedings of Agent, 2004:7-9.

U.S. Environmental Protection Agency. 2008. EPA water quality trading evaluation, final report, Washington, D. C. Available at: https://www.epa.gov/sites/production/files/ 2016-04/documents/wqt.pdf.

Weisbuch, G. 2000. "Environment and Institutions: A Complex Dynamical Systems Approach." Ecological Economics 35(3): 381-391.

Weisbuch, G., and G. Boudjema. 1999. "Dynamical Aspects in the Adoption of AgriEnvironmental Measures." Advances in Complex Systems 2(1): 11-36.

Welch, E.W., and F.J. Marc-Aurele Jr. 2001. "Determinants of Farmer Behavior: Adoption of and Compliance with Best Management Practices for Nonpoint Source Pollution in the Skaneateles Lake Watershed." Lake and Reservoir Management 17(3): 233-245.

Wilensky, U. 1999. "Center for Connected Learning and Computer-Based Modeling." In NetLogo. Northwestern University: http://ccl.northwestern.edu/

Winsten, J.R., and M. Hunter. 2011. "Using Pay-for-Performance Conservation to Address the Challenges of the Next Farm Bill." Journal of Soil and Water Conservation 66(4): 111A117A.

Wollni, M., and C. Andersson. 2014. "Spatial Patterns of Organic Agriculture Adoption: Evidence from Honduras." Ecological Economics 97(January): 120-28. https://doi.org/ 10.1016/j.ecolecon.2013.11.010.

Woodward, R.T., and R.A. Kaiser. 2002. "Market Structures for U.S. Water Quality Trading." Applied Economic Perspectives and Policy 24(2): 366-83. https://doi.org/10.1111/ 1467-9353.00025. 
Zhang, H., and Y. Vorobeychik. 2019. "Empirically Grounded Agent-Based Models of Innovation Diffusion: A Critical Review." Artificial Intelligence Review 52(1): 707-41. https://doi.org/10.1007/s10462-017-9577-z.

Zhang, W., R.S. Wilson, E. Burnett, E.G. Irwin, and J.F. Martin. 2016. "What Motivates Farmers to Apply Phosphorus at the 'Right' Time? Survey Evidence from the Western Lake Erie Basin." Journal of Great Lakes Research 42(6): 1343-56. https://doi.org/10.1016/j.jglr. 2016.08.007. 